\title{
Firm-Specific Investment, Sticky Prices, and the Taylor Principle*
}

\author{
Tommy Sveen ${ }^{\dagger} \quad$ Lutz Weinke ${ }^{\ddagger}$
}

October 24, 2004

\begin{abstract}
According to the Taylor principle a central bank should adjust the nominal interest rate by more than one-for-one in response to changes in current inflation. Most of the existing literature supports the view that by following this simple recommendation a central bank can avoid being a source of unnecessary fluctuations in economic activity. The present paper shows that this conclusion is not robust with respect to the modelling of capital accumulation. We use our insights to discuss the desirability of alternative interest rate rules. Our results suggest a reinterpretation of monetary policy under Volcker and Greenspan: The empirically plausible characterization of monetary policy can explain the stabilization of macroeconomic outcomes observed in the early eighties for the US economy. The Taylor principle in itself cannot.
\end{abstract}

Keywords: Sticky Prices, Aggregate Investment, Monetary Policy.

\section{JEL Classification: E22, E31}

*The authors are grateful to Jordi Galí. Thanks to Mikel Casares, Jinill Kim, Øistein Røisland, and seminar participants at Norges Bank and Universitat Pompeu Fabra for helpful comments. The usual disclaimer applies. The views expressed in this paper are those of the authors and should not be attributed to Norges Bank.

${ }^{\dagger}$ Research Department, Norges Bank, e-mail: tommy.sveen@norges-bank.no

$\ddagger$ Universitat Pompeu Fabra, e-mail: lutz.weinke@upf.edu 


\section{Introduction}

According to the Taylor principle a central bank should follow an active monetary policy, i.e. it should adjust the nominal interest rate by more than one-for-one in response to changes in current inflation. Simple interest rate rules consistent with that recommendation guarantee determinacy, i.e. local uniqueness of rational expectations equilibrium (REE), in many dynamic New-Keynesian (DNK) models. ${ }^{1}$ Given its apparent robustness Clarida et al. (2000), and a large subsequent literature, use the Taylor principle to judge the conduct of monetary policy in practice.

In the present paper we reassess the usefulness of the Taylor principle. Our model features Calvo pricing, combined with a convex capital adjustment cost at the firm level, i.e. we assume that capital is firm-specific. This set of assumptions has been originally proposed in Woodford (2003, Ch. 5). ${ }^{2}$ Surprisingly, we find that an active monetary policy is not a sufficient condition for determinacy. This is interesting because most of the existing literature supports the view that the Taylor principle is robust with respect to the modeling of capital accumulation. An exception is Dupor (2001). His result that a passive interest rate rule is required to guarantee determinacy appears, however, to be specific to the continuous time framework he employs. In a discrete-time model Galí et al. (2004) find that it is not endogenous capital per se that challenges the Taylor principle. ${ }^{3}$

How is it possible that we reach a different conclusion in the present paper? The answer is that the convenient and widely used assumption of a rental market for

\footnotetext{
${ }^{1}$ See, e.g., Taylor (1999) and Woodford (2001).

${ }^{2}$ Sveen and Weinke (2003, 2004a,b) explain the economic mechanism through which firm-specific capital affects inflation dynamics in the Calvo model. The latter has been obscured by a conceptual mistake in Woodford (2003, Ch. 5), as we note. Since we wrote and circulated our papers there have been other contributions that stress the fruitfulness of assuming firm-specific capital in a model with staggered price setting. See, e.g., Altig et al. (2004), Christiano (2004), Eichenbaum and Fisher (2004), and Woodford (2004).

${ }^{3}$ Lubik (2003) obtains a similar result. He finds that determinacy obtains under an active monetary policy, if conventional values are assigned to both the capital adjustment cost and the price stickiness parameter. His results are, however, extremely sensitive with respect to the choice of the capital adjustment cost parameter. Carlstrom and Fuerst (2003) find that forward-looking interest rate rules do generally not guarantee determinacy in a DNK model with capital accumulation. They do not challenge, however, the usefulness of the Taylor principle.
} 
capital is not innocuous: it hides an indeterminacy problem. The intuition is as follows. Current investment increases current marginal cost, but it lowers marginal cost in the future. A central bank that follows the Taylor principle therefore tends to decrease future real interest rates in the aftermath of an investment boom. Hence, to the extent that investment is forward-looking, the expectation of such a boom could potentially become self-fulfilling. Whether this possibility materializes, or not, depends on the degree of price stickiness. With sufficiently high price stickiness REE is indeterminate, as we will discuss. The last aspect is crucial for the fact that the rental market assumption hides an indeterminacy problem. As we show in Sveen and Weinke $(2003,2004 b)$ the difference between a specification with firm-specific capital and an alternative formulation with a rental market boils down to a difference in implied price stickiness: ${ }^{4}$ for any given exogenous restriction on price adjustment there is less price stickiness, if a rental market for capital is assumed. ${ }^{5}$ Importantly, with a rental market for capital the resulting price stickiness will generally be too low to make the indeterminacy issue appear to be relevant from a practical point of view. ${ }^{6}$ This conclusion changes if capital is assumed to be firm-specific: if a central bank respects the Taylor principle and follows a rule according to which the nominal interest rate is set as a function of inflation only, then indeterminacy appears to be the regular case.

Based on our results we reinterpret the conduct of monetary policy under Volcker and Greenspan. The analyzes in Clarida et al. (2000) and Lubik and Schorfheide (2004) suggest that the estimated change from a passive to an active monetary policy explains in itself the observed stabilization of economic outcomes. We amend their

\footnotetext{
${ }^{4}$ The intuition is analog to the one that explains the difference in implied inflation dynamics resulting from assuming either constant returns to scale or decreasing returns to scale in a DNK model, along the lines discussed in Sbordone (2002) and Galí et al. (2001).

${ }^{5}$ The difference in implied price stickiness is therefore a useful metric: Sveen and Weinke (2004b) show that, for a standard calibration of the two models, one needs a Calvo parameter of about 0.9 in the rental market model in order to obtain the equilibrium dynamics resulting form a value of 0.75 in the model with firm-specific capital.

${ }^{6}$ Carlstrom and Fuerst (2003) note that 'if prices are extremely sticky' the Taylor principle is no longer sufficient for determinacy.
} 
interpretation with a caveat: active monetary policy appears to guarantee desirable macroeconomic outcomes only if it is supplemented by interest rate smoothing, and/or some responsiveness of the nominal interest rate to a measure of economic activity. This is precisely the characterization of monetary policy which is empirically plausible under the Volcker-Greenspan tenure.

The remainder of the paper is organized as follows: Section 2 outlines the model structure with firm-specific capital and explains how it changes under the alternative assumption of a rental market for capital. Section 3 presents our results. In particular, we answer the following three questions. Why is the Taylor principle not sufficient for determinacy in a model with capital accumulation? Why is price stickiness crucial for the indeterminacy issue? Why do interest rate smoothing and responsiveness of the nominal interest rate to economic activity help guaranteeing determinacy? Section 4 concludes.

\section{The Model}

The economy is populated by households and firms. In what follows we reconsider the model with firm-specific capital outlined in Sveen and Weinke (2004a). ${ }^{7}$ In the present paper we assume, however, that there is no aggregate uncertainty except for sunspots according to which economic agents agree on a particular equilibrium. A short description of the rental market case is left for the last paragraph.

\subsection{Households}

Households choose consumption, supply labor in a competitive market, and have access to complete financial markets. A representative household seeks to maximize

\footnotetext{
${ }^{7}$ In Sveen and Weinke (2004a) we solve the model using an iterative procedure. In the present paper we follow Woodford (2004) and use the method of undetermined coefficients, which is computationally more efficient. See the Appendix for an outline of Woodford's solution.
} 
expected discounted utility:

$$
E_{t} \sum_{k=0}^{\infty} \beta^{k} U\left(C_{t+k}, N_{t+k}\right),
$$

where $U(\cdot)$ denotes the period utility function, $\beta$ is a discount factor, $N_{t}$ denotes hours worked in period $t$, and $C_{t}$ is a Dixit-Stiglitz consumption aggregate as of that time. Specifically,

$$
C_{t} \equiv\left(\int_{0}^{1} C_{t}(i)^{\frac{\varepsilon-1}{\varepsilon}} d i\right)^{\frac{\varepsilon}{\varepsilon-1}}
$$

where $\varepsilon$ is the elasticity of substitution between different varieties of goods $C_{t}(i)$.

We assume the following period utility function:

$$
U\left(C_{t}, N_{t}\right)=\frac{C_{t}^{1-\sigma}}{1-\sigma}-\frac{N_{t}^{1+\phi}}{1+\phi}
$$

Parameter $\sigma$ denotes the household's relative risk aversion, or equivalently, the inverse of the intertemporal elasticity of substitution, and parameter $\phi$ can be interpreted as the the inverse of the Frisch labor supply elasticity.

The maximization is subject to the following sequence of budget constraints:

$$
\int_{0}^{1} P_{t}(i) C_{t}(i) d i+E_{t}\left\{Q_{t, t+1} D_{t+1}\right\} \leq D_{t}+W_{t} N_{t}+T_{t}
$$

where $W_{t}$ is the time $t$ nominal wage, $Q_{t, t+1}$ is the stochastic discount factor for random nominal payments, $D_{t+1}$ is the nominal payoff of the portfolio held at the end of period $t$, and $T_{t}$ denotes profits resulting from ownership of firms.

For each variety of goods the consumption demand function reads:

$$
C_{t}^{d}(i)=\left(\frac{P_{t}(i)}{P_{t}}\right)^{-\varepsilon} C_{t},
$$

where $P_{t} \equiv\left(\int_{0}^{1} P_{t}(i)^{1-\varepsilon} d i\right)^{\frac{1}{1-\varepsilon}}$ denotes the price index. The latter has the property that the minimum expenditure required to purchase a bundle of goods resulting in 
$C_{t}$ units of the composite good is given by $P_{t} C_{t}$.

The remaining first order conditions associated with the household's problem are:

$$
\begin{aligned}
C_{t}^{\sigma} N_{t}^{\phi} & =\frac{W_{t}}{P_{t}} \\
\beta\left(\frac{C_{t+1}}{C_{t}}\right)^{-\sigma}\left(\frac{P_{t}}{P_{t+1}}\right) & =Q_{t, t+1} .
\end{aligned}
$$

The first equation is the optimality condition for labor supply, and the second one is a standard intertemporal optimality condition. Finally, let us note that the time $t$ gross nominal interest rate, $R_{t}$, is related to the stochastic discount factor by the equilibrium condition $R_{t}^{-1}=E_{t}\left\{Q_{t, t+1}\right\}$.

\section{$2.2 \quad$ Firms}

There is a continuum of monopolistically competitive firms, indexed on the unit interval. Each firm $i$ has access to a Cobb-Douglas technology:

$$
Y_{t}(i)=K_{t}(i)^{\alpha} N_{t}(i)^{1-\alpha}
$$

where $\alpha$ is the capital share in the production function, and $K_{t}(i)$ and $N_{t}(i)$ denote, respectively, firm $i$ 's capital stock and labor input used in its period $t$ production denoted $Y_{t}(i)$.

We assume staggered price setting à la Calvo (1983), i.e. each firm faces a constant and exogenous probability, $\theta$, of getting to reoptimize its price in any given period. This structure implies that firm $i$ 's nominal price, $P_{t}(i)$, is either the one that was posted the period before or the optimally chosen price $P_{t}^{*}(i)$.

Moreover, we follow Woodford (2003, Ch. 5) in assuming two restrictions on capital adjustment. First, the additional capital resulting from an investment decision becomes productive with a one period delay. Second, firms face a convex capital 
adjustment cost. $^{8}$ This is summarized in the following equation:

$$
I_{t}(i)=I\left(\frac{K_{t+1}(i)}{K_{t}(i)}\right) K_{t}(i)
$$

where $I_{t}(i)$ denotes the amount of the composite $\operatorname{good}^{9}$ purchased by firm $i$ at time $t$, and $K_{t}(i)$ denotes this firm's capital stock as of that period. Moreover, function $I(\cdot)$ is assumed to satisfy the following: $I(1)=\delta, I^{\prime}(1)=1$, and $I^{\prime \prime}(1)=\epsilon_{\psi}$. Parameter $\delta$ denotes the depreciation rate. Eichenbaum and Fisher (2004) interpret parameter $\epsilon_{\psi}$ as the elasticity of the investment to capital ratio with respect to Tobin's q, evaluated in steady state. Parameter $\epsilon_{\psi}$ is assumed to be strictly larger than zero and it measures the convex capital adjustment cost in a log-linear approximation to the equilibrium dynamics.

Cost minimization by firms and households implies that demand for each individual good $i$ in period $t$ can be written as follows:

$$
Y_{t}^{d}(i)=\left(\frac{P_{t}(i)}{P_{t}}\right)^{-\varepsilon} Y_{t}^{d},
$$

where $Y_{t}^{d}$ denotes aggregate demand at time $t$, which is given by:

$$
Y_{t}^{d} \equiv C_{t}+I_{t}
$$

and $I_{t} \equiv \int_{0}^{1} I_{t}(i) d i$ denotes aggregate investment demand.

Let us now consider a price setter's problem. Given its time $t$ capital stock, $K_{t}(i)$, a price setting firm $i$ chooses contingent plans for $\left\{P_{t+k}^{*}(i), K_{t+k+1}(i), N_{t+k}(i)\right\}_{k=0}^{\infty}$ in order to solve the following:

\footnotetext{
${ }^{8}$ Sveen and Weinke (2003) consider a model with just the first restriction on a firm's capital accumulation, namely the one period delay.

${ }^{9}$ The relevant elasticity of substitution is assumed to be the same as in the consumption aggregate.
} 


$$
\max \sum_{k=0}^{\infty} E_{t}\left\{Q_{t, t+k}\left[Y_{t+k}^{d}(i) P_{t+k}(i)-W_{t+k} N_{t+k}(i)-P_{t+k} I_{t+k}(i)\right]\right\}
$$

s.t.

$$
\begin{aligned}
Y_{t+k}^{d}(i) & =\left(\frac{P_{t+k}(i)}{P_{t+k}}\right)^{-\varepsilon} Y_{t+k}^{d}, \\
Y_{t+k}^{d}(i) & \leq N_{t+k}(i)^{1-\alpha} K_{t+k}(i)^{\alpha}, \\
I_{t+k}(i) & =I\left(\frac{K_{t+k+1}(i)}{K_{t+k}(i)}\right) K_{t+k}(i), \\
P_{t+k+1}(i) & = \begin{cases}P_{t+k+1}^{*}(i) & \text { with prob. }(1-\theta) \\
P_{t+k}(i) & \text { with prob. } \theta\end{cases}
\end{aligned}
$$

A firm $j$ that is restricted to change its price at time $t$ solves the same problem, except for the fact that it takes $P_{t}(j)$ as given.

The first order condition for capital accumulation reads:

$$
\frac{d I_{t}(i)}{d K_{t+1}(i)} P_{t}=E_{t}\left\{Q_{t, t+1}\left[M S_{t+1}(i)-\frac{d I_{t+1}(i)}{d K_{t+1}(i)} P_{t+1}\right]\right\}
$$

where $M S_{t+1}(i)$ denotes the nominal reduction in firm $i$ 's labor cost associated with having one additional unit of capital in place in period $t+1$. The only non-standard feature of the last equation is that the marginal return to capital is not measured by the nominal marginal revenue product of capital, but instead by $M S_{t+1}(i)$. The reason is that firms are demand constrained, as discussed in Woodford (2003, Ch. $5)$.

The following relationship holds true:

$$
M S_{t}(i)=W_{t} \frac{M P K_{t}(i)}{M P L_{t}(i)}
$$

where $M P K_{t}(i)$ and $M P L_{t}(i)$ denote, respectively, the marginal product of capital and labor of firm $i$ in period $t$. 
The first order condition for price setting is given by:

$$
\sum_{k=0}^{\infty} \theta^{k} E_{t}\left\{Q_{t, t+k} Y_{t+k}^{d}(i)\left[P_{t}^{*}(i)-\mu M C_{t+k}(i)\right]\right\}=0,
$$

where $\mu \equiv \frac{\varepsilon}{\varepsilon-1}$ denotes the frictionless mark-up over marginal costs, and $M C_{t}(i)$ denotes the nominal marginal cost of firm $i$ in period $t .{ }^{10}$ The latter is given by:

$$
M C_{t}(i)=\frac{W_{t}}{M P L_{t}(i)}
$$

Equation (14) reflects the forward-looking nature of price setting: firms take into account not only current but also future expected marginal costs in those states of the world where the chosen price is still posted.

\subsection{Market Clearing}

Clearing of the labor market requires that hours worked, $N_{t}$, are given by the following equation, which holds for all $t$ :

$$
N_{t}=\int_{0}^{1} N_{t}(i) d i
$$

Finally, market clearing for each variety $i$ requires at each point in time:

$$
Y_{t}(i)=C_{t}^{d}(i)+I_{t}^{d}(i)
$$

where $I_{t}^{d}(i)$ denotes time $t$ investment demand for good $i$.

\footnotetext{
${ }^{10} \mathrm{We}$ follow a large literature on the Calvo model in using the notation $E_{t}$ in equation (14) to indicate an expectation that is conditional on the time $t$ state of the world, but integrating only over those future states in which firm $i$ has not reset its price since period $t$. Woodford (2004) uses $\widehat{E}_{t}^{i}$ in order to denote this expectation.
} 


\subsection{Some Linearized Equilibrium Conditions}

We restrict attention to a linear approximation around a steady state with zero inflation. Throughout, a hat on a variable denotes the percent deviation of the original variable with respect to its steady state value.

\subsubsection{Households}

Solving the household's problem results in an Euler equation and in a labor supply equation. They read, respectively:

$$
\begin{aligned}
\widehat{C}_{t} & =E_{t} \widehat{C}_{t+1}-\frac{1}{\sigma}\left(i_{t}-E_{t} \pi_{t+1}-\rho\right), \\
\left(\frac{W_{t}}{P_{t}}\right) & =\phi \widehat{N}_{t}+\sigma \widehat{C}_{t}
\end{aligned}
$$

where $i_{t} \equiv \log R_{t}$ denotes the time $t$ nominal interest rate, and $\pi_{t} \equiv \log \left(\frac{P_{t}}{P_{t-1}}\right)$ is time $t$ inflation.

\subsubsection{Firms}

Aggregating and log-linearizing the first order condition for investment (12) and combining the resulting expression with the Euler equation (18), we obtain:

$$
\begin{aligned}
\widehat{K}_{t+1}= & \frac{1}{1+\beta} \widehat{K}_{t}+\frac{\beta}{(1+\beta)} E_{t} \widehat{K}_{t+2} \\
& +\frac{1-\beta(1-\delta)}{\epsilon_{\psi}(1+\beta)} E_{t} \widehat{m s}_{t+1}-\frac{1}{\epsilon_{\psi}(1+\beta)}\left(i_{t}-E_{t} \pi_{t+1}-\rho\right),
\end{aligned}
$$

where $K_{t} \equiv \int_{0}^{1} K_{t}(i) d i$ is the aggregate time $t$ capital stock, and $m s_{t} \equiv \int_{0}^{1} \frac{M S_{t}(i)}{P_{t}} d i$ denotes the average real marginal return to capital.

We follow Woodford (2004) and derive the inflation equation by employing the method of undetermined coefficients. He shows that it takes the following simple form:

$$
\pi_{t}=\beta E_{t} \pi_{t+1}+\kappa \widehat{m c}_{t},
$$


where $\kappa$ is a parameter which is computed numerically, and $m c_{t} \equiv \int_{0}^{1} \frac{M C_{t}(i)}{P_{t}} d i$ is the average real marginal cost.

Aggregating and log-linearizing the production functions of individual firms (8) results in:

$$
\widehat{Y}_{t}=\alpha \widehat{K}_{t}+(1-\alpha) \widehat{N}_{t}
$$

where $Y_{t} \equiv K_{t}^{\alpha} N_{t}^{1-\alpha}$ is aggregate production, up to the first order.

\subsubsection{Market clearing}

Aggregating and log-linearizing the goods market clearing condition for each variety (17) we obtain:

$$
\widehat{Y}_{t}=\zeta \widehat{C}_{t}+\frac{1-\zeta}{\delta}\left[\widehat{K}_{t+1}-(1-\delta) \widehat{K}_{t}\right]
$$

where $\zeta \equiv \frac{\rho+\delta(1-\alpha)}{\rho+\delta}$ denotes the steady state consumption to output ratio, and $\frac{(1-\zeta)}{\delta}$ is the steady state capital to output ratio.

\subsection{Rental Market}

Let us now assume that households accumulate the capital stock and rent it to firms. ${ }^{11}$ This structure implies that each firm produces at the same marginal cost which is independent of the quantity supplied by any individual firm. The associated inflation equation reads:

$$
\pi_{t}=\beta E_{t} \pi_{t+1}+\lambda \widehat{m c},
$$

where $\lambda \equiv \frac{(1-\beta \theta)(1-\theta)}{\theta}$. It should be noted that the inflation equation is the only linearized equilibrium condition that is affected by the change in assumption regarding capital accumulation. This means that, given a specification of monetary policy, the equilibrium processes for the nominal interest rate, consumption, real wage, capital, output, hours, and inflation are determined by equations (18), (19), (20), (22), (23),

\footnotetext{
${ }^{11}$ The implied changes in the respective maximization problems of households and firms are obvious. See, e.g., Galí (2004) et al. for a derivation of the equilibrium conditions resulting from that set of assumptions.
} 
and an inflation equation. The latter is given by equation (21) for the firm-specific capital model and by equation (24) for the rental market specification. ${ }^{12}$

\section{Results}

Our goal is to explore what are desirable features of interest rate rules in the sense that they guarantee determinacy. Importantly, the theoretical framework developed so far can be used to explain why some rules are more desirable than others, as we will see. Finally, we will show that our results are also useful from a positive point of view. They call for a reinterpretation of the conduct of U.S. monetary policy under Volcker and Greenspan.

\subsection{Calibration}

The period length is one quarter. Consistent with empirical estimates of the intertemporal elasticity of substitution given by Basu and Kimball (2003) we assume $\sigma=2$. We set $\phi=1$, implying a unit labor supply elasticity. We assign a standard value of 0.36 to the capital share in the production function, $\alpha$. Setting $\beta=0.99$ implies an average annual real return of about 4 percent. We choose $\varepsilon=11$ implying a frictionless markup of 10 percent, which is in line with the empirical estimate in Galí et al. (2001). Finally, we set $\epsilon_{\psi}=3$, as proposed by Woodford (2003, Ch. 5).

\footnotetext{
${ }^{12}$ To solve the dynamic stochastic system of equations we use Dynare (http://www.cepremap.cnrs.fr/dynare/). Thanks to Larry Christiano for providing us with Matlab code which we have used in the computation of $\kappa$.
} 


\subsection{A Simple Interest Rate Rule}

Our starting point is a simple rule according to which the nominal interest rate is set as a function of current inflation:

$$
i_{t}=\rho+\tau_{\pi} \pi_{t}
$$

We ask what combinations of values for the inflation response coefficient, $\tau_{\pi}$, and the price stickiness parameter, $\theta$, result in a determinate equilibrium. The result is shown in Figure 1 for the model with firm-specific capital: a large range of parameter values that meet the Taylor principle are inconsistent with determinacy. ${ }^{13}$ An inflation response coefficient, $\tau_{\pi}$, strictly larger than one is necessary but not sufficient for determinacy. Next we develop the intuition behind this result.

We focus on the role of capital accumulation for equilibrium dynamics. Let us start by conducting a thought experiment. Suppose a sunspot hits the economy and firms increase their investment spending without any change in the economy's fundamentals justifying it. Could this investment boom be potentially consistent with equilibrium? The answer is yes and the reason is simple. Investment has counteracting effects on the determination of the marginal cost. It increases current marginal cost but it reduces marginal cost in subsequent periods. The resulting inflation dynamics inherit the U-shaped marginal cost pattern. In particular, there will be some period of deflation in the aftermath of the investment boom. To the extent that the central bank follows the Taylor principle, the associated real interest rate will therefore drop in the deflationary period. The latter could potentially result in a drop in the long real interest rate relevant for investment. ${ }^{14}$ If the drop is sufficiently large, then it may rationalize the investment boom ex post. ${ }^{15}$

\footnotetext{
${ }^{13}$ There is also a standard indeterminacy region in Figure 1. The latter is associated with the case where the Taylor principle is not met. As one may expect, the dimension of the standard indeterminacy is one.

${ }^{14}$ The long real rate relevant for investment can be written as: $r r_{t}^{\text {long }}=\rho+$ $E_{t} \sum_{k=0}^{\infty} \beta^{k}\left(r r_{t+k}-\rho\right)$, which is obvious from eqaution (20).

${ }^{15}$ The reason for the word 'sufficiently' is that the average marginal savings in labor costs will
} 


\section{[Figure 1 about here]}

Whether this possibility materializes, or not, depends on both the price stickiness parameter, $\theta$, and the inflation response coefficient, $\tau_{\pi}$, as shown in Figure $1 .{ }^{16}$ In order to disentangle the respective roles of the two parameters it is useful to take a detour. Let us consider, for a moment, an economy which is identical to the one with endogenous firm-specific capital, except for the fact that capital accumulation at the firm level is assumed to follow an exogenous stochastic process. The latter is common to all firms and, specifically, it is assumed to take the following form: $\widehat{K}_{t+1}=$ $(1-\delta) \widehat{K}_{t}+e_{t}$, where $e_{t}$ is $i . i . d$. with zero mean. The inflation equation resulting from that set of assumptions reads: $\pi_{t}=\beta E_{t} \pi_{t+1}+\xi \widehat{m c}_{t}$, with $\xi \equiv \lambda \frac{1-\alpha}{1+\alpha(\varepsilon-1)} \cdot{ }^{17}$ The latter equation differs from the one implied by the model with endogenous firm-specific capital. However, this difference is negligible, as we show and discuss in Sveen and Weinke (2004a). The simple exogenous investment economy is therefore a useful apparatus to analyze the economic mechanisms behind the results shown in Figure 1. First, we turn to the role of price stickiness. To this end we study impulse responses associated with a $10 \%$ increase in exogenous investment spending relative to its steady state level. The inflation response coefficient, $\tau_{\pi}$, is set to 1.1 , implying that the Taylor principle is met.

\section{[Figure 2 about here]}

also tend to decrease in the considered economic situation. We will come back to this point.

${ }^{16}$ The indeterminacy region associated with the case where the Taylor principle is met does not lend itself for a simulation of the sunspot since the dimension of indeterminacy is two. For a discussion of the last point see Galí (1997) and the references herein. Therefore, our thought experiment illustartes only one from among a continuum of possible responses of the endogenous variables to a sunspot shock. In doing so it highlights, however, the key economic mechanism behind our results, namely the role of investment spending for the marginal cost dynamics.

${ }^{17}$ It should be noted that this equation takes the same form as the one implied by assuming a constant capital stock at the firm level, as analyzed in Sbordone (2002) and Galí et al. (2001). 
As shown in Figure 2, the assumed degree of price stickiness is critical for the response of the long real rate. For a value of the price stickiness parameter, $\theta$, equal to 0.6 the long real rate increases on impact, whereas it decreases if a value of 0.75 is assigned to this parameter. The more forward-looking price setting is the less do prices increase on impact. The reason is as follows. With higher price stickiness the expected future reduction in marginal cost resulting from the investment shock affects current price setting more strongly. ${ }^{18}$ Hence, higher price stickiness dampens the increase in the current real interest rate on impact. If the current real rate is sufficiently stable, then the long real rate drops on impact.

This insight from the simple exogenous investment economy helps understanding the role of price stickiness for indeterminacy in the model with endogenous firmspecific capital. Indeed, under an interest rate rule that respects the Taylor principle, a price stickiness parameter, $\theta$, of about 0.63 is needed to obtain indeterminacy, as shown in Figure 1. This value corresponds to an average lifetime of a price of less than 3 quarters. Of course, the exact extent to which prices are sticky in actual economies remains controversial. However, a value of $\theta$ as high as 0.75 is often considered to be empirically plausible. ${ }^{19}$

Second, we analyze the role of the inflation response coefficient, $\tau_{\pi}$, for the results shown in Figure 1. In order to gather the intuition behind our findings we reconsider the simple exogenous investment economy. The price stickiness parameter, $\theta$, is set to 0.75 and we analyze impulse responses associated with an investment shock, as specified above. If the inflation response coefficinet, $\tau_{\pi}$, is set to 1.1 , then the long real rate drops on impact, while the opposite holds true for a parameter value of 4 . This is shown in Figure 3.

\section{[Figure 3 about here]}

\footnotetext{
${ }^{18}$ Clearly, the degree of price stickiness affects not only the forward-lookingness of price setting but also the extent to which the marginal cost changes after the shock. However, our simulation results justify the simple intuition given in the text.

${ }^{19}$ The micro evidence on price adjustements is mixed. Golosov and Lucas (2003) suggest that firms change prices on average about every 2 quarters. Baudry et al. (2004) find, however, a value of 3 quarters, while the analysis conducted in Aucremanne and Dhyne (2004) suggests 5 quarters.
} 
We have outlined already the intuition for why the long real rate drops on impact for empirically plausible specifications of the inflation response coefficient and the price stickiness parameter. The apparently counterintuitive finding in Figure 3 is that the impact response of the long real rate changes sign for a very aggressive monetary policy rule. This is, however, for a simple reason. We observe that the central bank is more effective in reducing future deflation than in reducing current inflation: an increase in the response parameter decreases future deflation, which in itself tends to increase current inflation. Hence, if monetary policy is sufficiently aggressive and future expected deflation is low, then the relevant long real interest rate must increase rather than decrease on impact in response to an investment shock.

Once more, the simple exogenous investment economy helps understanding the results in Figure 1. Indeed, we find that from among the rules which meet the Taylor principle very aggressive rules and intermediate rules, as measured by the relative size of the respective inflation response coefficients, have crucially different properties: the former rules guarantee determinacy, whereas the latter do not. ${ }^{20} \mathrm{~A}$ maybe somewhat surprising result in Figure 1 is that there also exists a determinacy region associated with rules that respect the Taylor principle but prescribe a very gentle interest rate response to inflation. Our explanation is as follows. If the long real rate does not change by much then the drop in marginal savings associated with an investment boom will render REE determinate.

What is the relevance of our indeterminacy results? In related literature Edge and Rudd (2002) and Røisland (2003) make the case against too gentle interest rate rules, while Orphanides (2001) points out that too aggressive interst rate rules are undesirable. ${ }^{21}$ Combining their findings with ours we conclude that the Taylor

\footnotetext{
${ }^{20}$ Obviously, this claim is conditional on a specification of the price stickiness parameter that we have previously characterized as being empirically plausible.

${ }^{21}$ Edge and Rudd (2002) and Røisland (2003) obtain their results from a simple observation: taxes are paid on nominal capital income, which calls for a strengthening of the Taylor principle. On the other hand, Orphanides (2001) argues that very aggressive interest rate rules have the undesirable property of amplifying mistakes in the conduct of monetary policy.
} 
principle is a poor guide for the design of monetary policy.

\section{[Figure 4 about here]}

As we have argued, forward-looking price setting is one key economic mechanism behind our results. Indeed, to the extent that a rental market for capital is assumed price setting is not forward-looking enough to imply indeterminacy, unless extreme assumptions regarding the frequency of price adjustment are made. This is shown in Figure 4. These findings are consistent with those reported by Carlstrom and Fuerst (2003).

In summary, abstracting from capital accumulation, i.e. considering only consumption demand, which does not produce any counteracting effects for the determination of the marginal cost, or using the rental market assumption, which reduces the implied price stickiness in the model, obscures the fact that the Taylor principle is not a useful guide for the design of monetary policy. What form should simple interest rate rules then take in order to prevent the central bank from becoming a source of macroeconomic instability?

\subsection{More Prominent Interest Rate Rules}

We analyze the desirabilty of some interest rate rules that have been proposed in the literature, either on normative grounds or as an empirically relevant description of the conduct of monetary policy in practice. As in the previous section our criterion to assess the performance of a particular interest rate rule is whether or not it guarantees determinacy.

\subsubsection{Responding to Economic Activity}

Let us consider first the indeterminacy regions associated with an interest rate rule that allows for an output response, in the spirit of Taylor (1993):

$$
i_{t}=\rho+\tau_{\pi} \pi_{t}+\tau_{y} \widehat{Y}_{t} .
$$




\section{[Figure 5 about here]}

A relatively small size of the output response coefficient is sufficient to reduce dramatically the importance of the indeterminacy issue, as shown in Figure 5. The intuition is straightforward from the thought experiment of an investment boom. The latter is associated with an increase in current output. If the central bank reacts with its interest rate instrument directly to this, then the impact of current investment spending on future marginal cost will generally not result in a monetary policy which would justify an investment boom ex post. The last result amends a recent finding by Schmitt-Grohé and Uribe (2004) with a caveat. They study the welfare properties of alternative interest rate rules across a rich variety of DNK models. Using a second order approximation they argue that responding to output is costly in welfare terms. ${ }^{22}$ However, based on our analysis, reacting to some measure of real activity will generally prevent the central bank from becoming a source of unnecessary fluctuations in the economy. This aspect is absent in their analysis, just because the rental market assumption hides a relevant indeterminacy problem. Of course, an obvious question is whether or not there exist alternative interest rate rules which have the property of guaranteeing determinacy (at a possibly smaller welfare cost).

\subsubsection{Interest Rate Smoothing}

Let us analyze next the performance of interest rate rules which take the following form:

$$
i_{t}=\rho_{i} i_{t-1}+\left(1-\rho_{i}\right)\left(\rho+\tau_{\pi} \pi_{t}\right) .
$$

With interest rate smoothing the definition of the Taylor principle becomes that monetary policy should be active in the long run. In a model without capital the so defined Taylor principle guarantees determincay. This means that the particular

\footnotetext{
${ }^{22}$ It should be noted that the analysis in Schmitt-Grohé and Uribe (2004) does not imply that it would be costly in welfare terms to respond to some output gap measure. However, it is unclear a priori how natural output should be defined in a model with endogenous capital, as discussed in Woodford (2003, Ch. 5).
} 
value of the interest rate smoothing coefficient, $\rho_{i} \in(0,1)$, is irrelevant for indeterminacy, as long as the inflation response coefficient, $\tau_{\pi}$, is strictly larger than one. Schmitt-Grohé and Uribe (2004) argue that this insight is robust with respect to the modeling of capital accumulation. We find, however, that the role of interest rate smoothing changes substantially if capital is firm-specific. This is shown in Figure 6. For a value of $\tau_{\pi}$ strictly larger than one it is not true that determincy would obtain for all $\rho_{i} \in(0,1) .{ }^{23}$ To our best knowledge this observation is new in the literature. $^{24}$

\section{[Figure 6 about here]}

The intuition behind this finding is in line with our previous interpretations of the model. Let us reconsider the thought experiment of an investment boom that is not justified by a change in the economy's fundamentals. To the extent that the central bank behaves in a backward-looking manner the initial increase in inflation associated with the boom will keep being relevant for the determination of future (real) rates. Hence, indeterminacy can be ruled out in this case: the future expected reduction in marginal cost associated with the investment boom does not dominate the determination of the long rate relevant for investment. We therefore find that interest rate smoothing and responding to real activity are both desirable properties of interest rate rules, in the sense that they help guranteeing determinacy. Clearly, a second order approximation to the equilibrium dynamics is required in order to tell which one of the two features is preferable from a welfare point of view. This is an interesting line for future research. ${ }^{25}$

\footnotetext{
${ }^{23}$ This is, again, conditional on what we have characterized as an empirically plausible specification of price stickiness.

${ }^{24}$ In particular, the focus in Benhabib et al. (2003) is different from ours. They conduct a global analysis and make the case for super-inertial rules (i.e. rules where $i_{t}$ on the left hand side of equation (27) is replaced by $\Delta i_{t}$, and $\Delta$ is the first-difference operator). Rules of this type have also been advocated based on local analysis. See, e.g., Rotemberg and Woodford (1999).

${ }^{25}$ It should be emphasized that the results from such an analysis are not trivial given the findings in Schmitt-Grohé and Uribe (2004). The reason is that a rental market model and a specification with firm-specific capital do not just differ in the inflation equation if the order of approximation to the equilibrium dynamics is higher than one.
} 
Our results regarding the desirability of alternative arrangements for the conduct of monetary policy are also interesting from a positive point of view. The analyzes in Clarida et al. (2000) and Lubik and Schorfheide (2004) appear to imply that the estimated change from a passive to an active monetary policy explains in itself the stabilization of macroeconomic outcomes in the U.S. that has been observed in the early 1980's. We take the occurrence of self-fulfilling expectations, or lack thereof, as a possible explanation for the observed reduction in macroeconomic instability under the Volcker-Greenspan tenure. ${ }^{26}$ However, viewed through the lense of a DNK model with firm-specific capital, the interpretation of their empirical results changes: active monetary policy appears to guarantee desirable macroeconomic outcomes only if it is supplemented by interest rate smoothing, and/or some responsiveness of the nominal interest rate to a measure of economic activity. Interestingly, this is precisely the characterization of monetary policy which is empirically plausible under the Volcker-Greenspan tenure.

\section{Conclusion}

According to the Taylor principle a central bank should adjust the nominal interest rate by more than one-for-one in response to changes in current inflation. This recommendation is generally believed to be a useful guide for the design of monetary policy. We find, however, that by following the Taylor principle a central bank does not necessarily avoid becoming a source of marcoeconomic instability. More importantly, to the extent that a central bank adjusts the nominal interest rate in response to inflation only, indeterminacy appears to be the regular case. This challenges much of the conventional wisdom regarding desirable features of interest rate rules.

The reason for why our results differ from those that have been obtained in the

\footnotetext{
${ }^{26}$ For a discussion of alternative hypotheses that explain this change in macroeconomic outcomes, see Lubik and Schorfheide (2004).
} 
existing literature lies in the fact that we model a simultaneous price setting and investment decision at the firm level, instead of focusing on the price setting decision alone. Our results follow from an interaction of two economic mechanisms: forwardlookingness in investment and in price setting. In explaining these mechanisms we build on our earlier work where Sveen and Weinke (2003, 2004a,b) solve and discuss models with firm-specific capital and Calvo pricing.

Based on our insights we make the case for interest rate rules prescribing that the central bank should allow for some interest rate smoothing and/or react to some measure of economic activity. We also use our theoretical results to reinterpret the empirical estimates in Clarida et al. (2000) and Lubik and Schorfheide (2004). It is not plausible that active monetary policy in itself would have stabilized the economy. Our interpretation is that the whole design of monetary policy is crucial: active monetary policy appears to guarantee desirable macroeconomic outcomes only if it is supplemented by interest rate smoothing, and/or some responsiveness of the nominal interest rate to a measure of economic activity. This interpretation is consistent with both our theory and their empirical estimates. 


\section{Appendix: Inflation Dynamics}

Woodford (2004) posits that the price chosen by a Calvo price setter $i$ is:

$$
\widehat{p}_{t}^{*}(i)=\widehat{p}_{t}^{*}-\tau_{1} \widehat{k}_{t}(i)
$$

where $k(i) \equiv \frac{K_{t}(i)}{K_{t}}, p_{t}^{*}(i) \equiv \frac{P_{t}^{*}(i)}{P_{t}}$, and $\tau_{1}$ is an unknown parameter. He further assumes that the investment decision of any firm $j$ satisfies:

$$
\widehat{k}_{t+1}(j)=\tau_{2} \widehat{k}_{t}(j)+\tau_{3} \widehat{p}_{t}(j)
$$

where $p_{t}(j) \equiv \frac{P_{t}(j)}{P_{t}}$, and $\tau_{2}$ and $\tau_{3}$ are two additional unknown parameters.

Finally, he invokes the relationship between the log-linearized average newly set price, $\widehat{p}_{t}^{*}$, and inflation, $\pi_{t}$ :

$$
\pi_{t}=\frac{1-\theta}{\theta} \widehat{p}_{t}^{*}
$$

Combined with the first-order conditions for price setting and investment it is possible to pin down the unknown coefficients $\tau_{1}, \tau_{2}$, and $\tau_{3}$ and to derive the inflation equation (21), along the lines outlined in Woodford (2004). 


\section{References}

Altig, David, Lawrence J. Christiano, Martin Eichenbaum, and Jesper Lindé (2004):

"Firm-Specific Capital, Nominal Rigidities, and the Business Cycle", mimeo.

Aucremanne, Luc, and Emmanuel Dhyne (2004): "How Frequently do Prices Change? Evidence Based on the Micro Data Underlying the Belgian CPI", European Central Bank Working Paper No. 331.

Basu, Susanto, and Miles S. Kimball (2003): "Investment Planning Costs and the Effects of Fiscal and Monetary Policy", mimeo.

Baudry, Laurent, Hervé Le Bihan, Patrick Sevestre, and Sylvie Tarrieu (2004): "Price Rigidity. Evidence from the French CPI Micro-Data", European Central Bank Working Paper No. 331.

Benhabib, Jess, Stephanie Schmitt-Grohé, and Martin Uribe (2003): "BackwardLooking Interest-Rate Rules, Interest-Rate Smoothing, and Macroeconomic Instability", Journal of Money, Credit, and Banking, 35(6), 1379-1412.

Calvo, Guillermo (1983): "Staggered Prices in a Utility Maximizing Framework", Journal of Monetary Economics, 12(3), 383-398.

Carlstrom, Charles T., and Timothy S. Fuerst (2003): "Investment and Interest Rate Policy: A Discrete Time Analysis", Federal Reserve Bank of Cleveland Working Paper 03/20.

Christiano, Lawrence J. (2004): "Firm-Specific Capital and Aggregate Inflation Dynamics in Woodford's Model", mimeo.

Clarida, Richard, Jordi Galí, and Mark Gertler (2000): "Monetary Policy Rules and Macroeconomic Stability: Evidence and Some Theory", Quarterly Journal of Economics, 115(1), 147-80.

Dupor, Bill (2001): "Investment and Interest Rate Policy", Journal of Economic Theory, 98 May, 85-113. 
Edge, Rochelle M., and Jeremy B. Rudd (2002): "Taxation and the Taylor Principle", Federal Reserve Board, Finance and Economics Discussion Series No. 2002-51. Eichenbaum, Martin and Jonas D. M. Fisher (2004): "Evaluating the Calvo Model of Sticky Prices", NBER Working Paper 10617.

Galí, Jordi (1997): "Solving Linear Dynamic Models with Sunspot Equilibria: A Note", mimeo, New York University.

Galí, Jordi, Mark Gertler, and David López-Salido (2001): "European Inflation Dynamics", European Economic Review, 45(7), 1237-1270.

Galí, Jordi, Mark Gertler, David López-Salido, and Javier Vallés (2004): "Ruleof-Thumb Consumers and the Design of Interest Rate Rules", mimeo, Universitat Pompeu Fabra.

Golosov, M., and R.E. Lucas, Jr. (2003): "Menu Costs and Phillips Curves", NBER Working Paper 10187.

Lubik, Thomas A. (2003): "Investment Spending, Equilibrium Indeterminacy, and the Interactions of Monetary and Fiscal Policy", mimeo, Johns Hopkins University. Lubik, Thomas A., and Frank Schorfheide (2004): "Testing for Indeterminacy: An Application to U.S. Monetary Policy", American Economic Review, 94(1), 190-217. Orphanides, Athanasios (2001): "Monetary Policy Rules Based on Real-Time Data", American Economic Review, 91(4), 964-985.

Rotemberg, Julio, and Michael Woodford (1999): "Interest-Rate Rules in an Estimated Sticky-Price Model", in John B. Taylor, ed., Monetary Policy Rules, Chicago: University of Chicago Press, 57-119.

Røisland, Øistein (2003): "Capital Income Taxation, Equilibrium Determinacy, and the Taylor Principle", Economics Letters, 81, 147-153.

Sbordone, Argia M. (2002): "Prices and Unit Labor Costs: A New Test of Price Stickiness", Journal of Monetary Economics, 49(2), 265-292. 
Schmitt-Grohé, Stephanie, and Martin Uribe (2004): "Optimal Simple and Implementable Monetary and Fiscal Rules", NBER Working Paper 10253.

Sveen, Tommy, and Lutz Weinke (2003): "Inflation and Output Dynamics with Firm-owned Capital", Universitat Pompeu Fabra Working Paper 702.

Sveen, Tommy, and Lutz Weinke (2004a): "Pitfalls in the Modelling of ForwardLooking Price Setting and Investment Decisions", Central Bank of Norway (Norges Bank) Working Paper 2004/1.

Sveen, Tommy, and Lutz Weinke (2004b): "New Perspectives on Capital and Sticky Prices", Central Bank of Norway (Norges Bank) Working Paper 2004/3.

Taylor, John B. (1993): "Discretion versus Policy Rules in Practice", CarnegieRochester Conference Series on Public Policy, 39, 195-214.

Taylor, John B. (1999): "A Historical Analysis of Monetary Policy Rules", in John B. Taylor, ed., Monetary Policy Rules, Chicago: University of Chicago Press, 319341.

Woodford, Michael (2001): "The Taylor Rule and Optimal Monetary Policy", American Economic Review, 91(2), 232-237.

Woodford, Michael (2003): Interest and Prices: Foundations of a Theory of Monetary Policy, Princeton: Princeton University Press.

Woodford, Michael (2004): "Inflation and Output Dynamics with Firm-specific Capital", mimeo, Princeton University. 


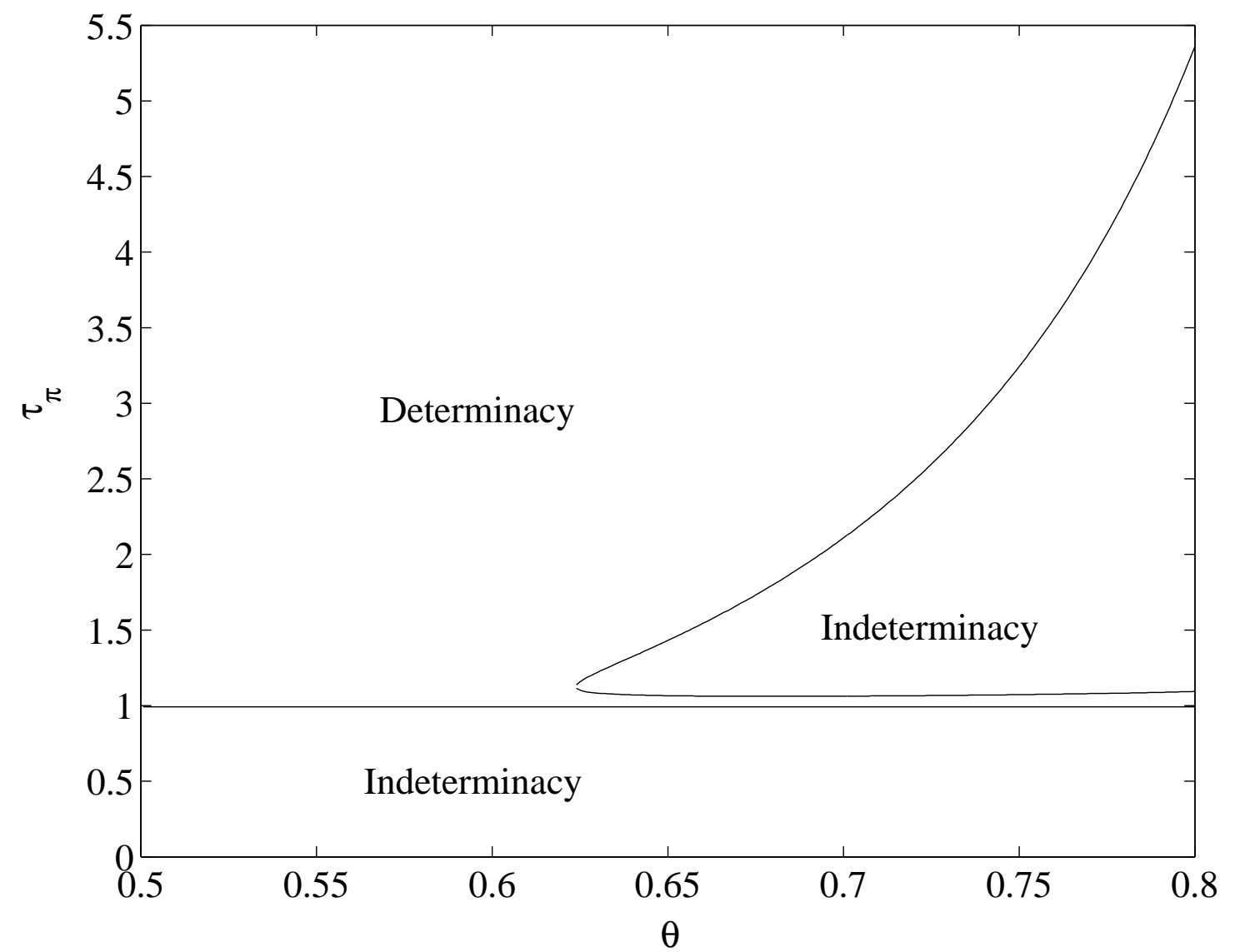

Figure 1: Indeterminacy with Firm-Specific Investment 

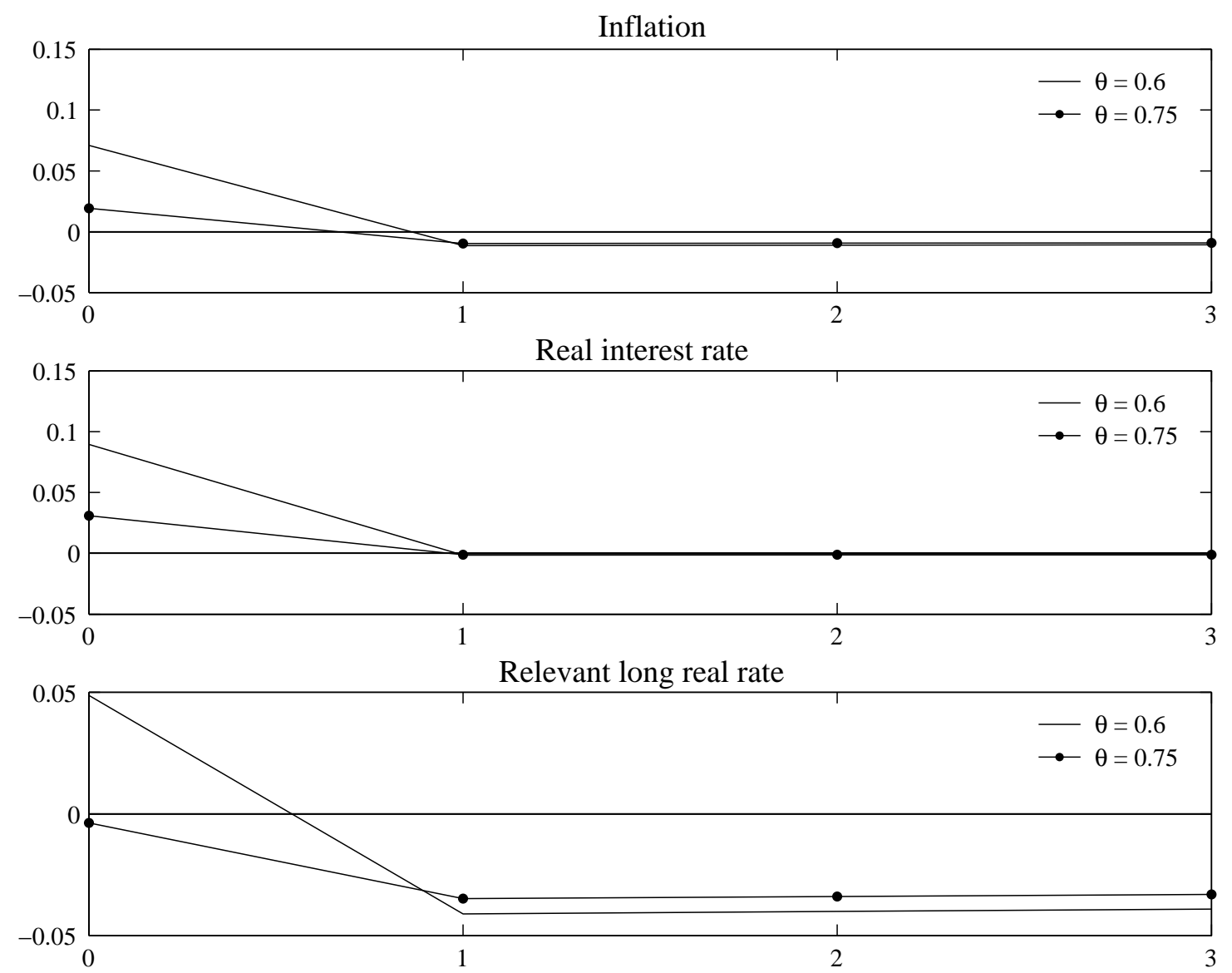

Figure 2: Different Price Stickiness Parameters in the Exogenous Investment Model 

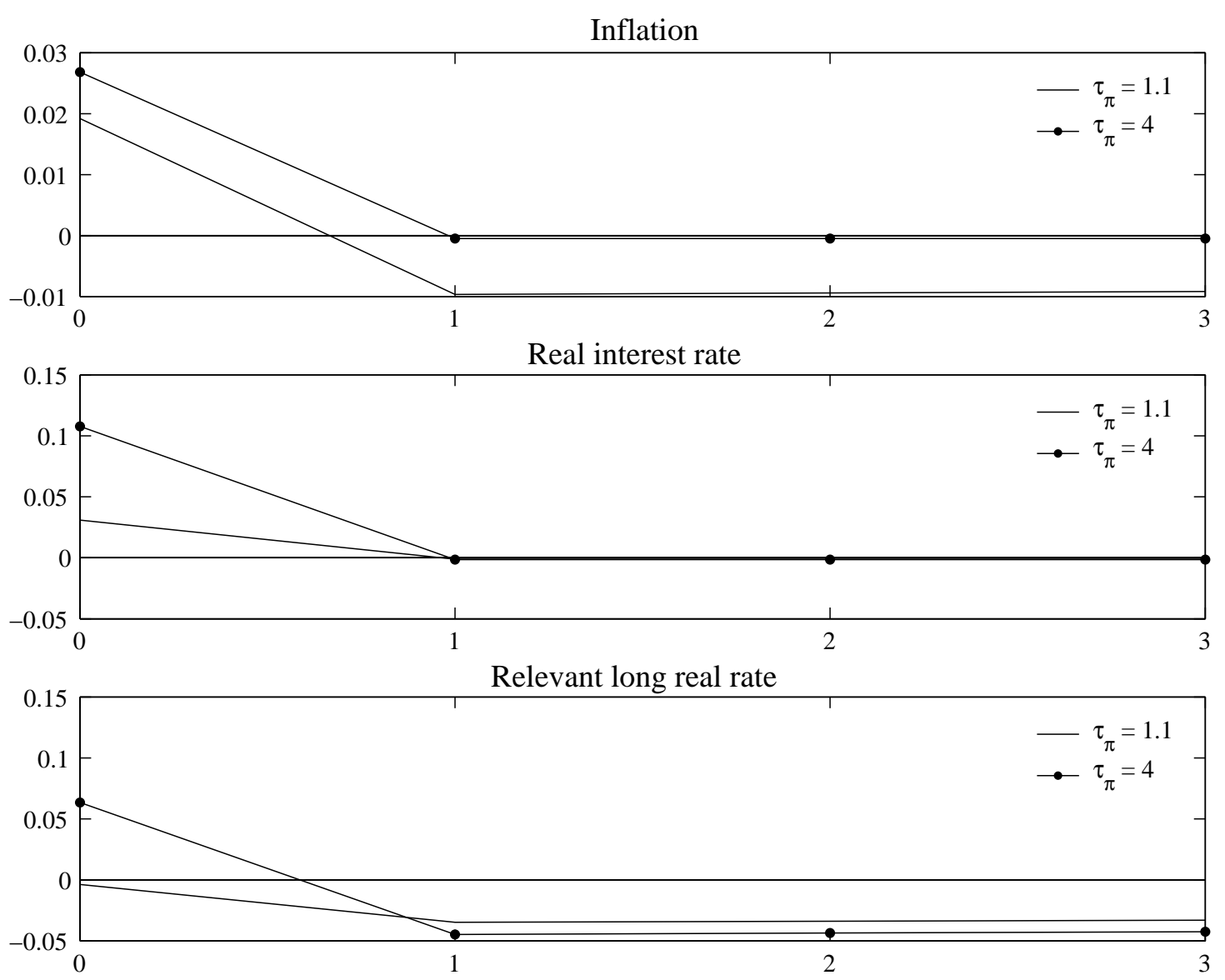

Figure 3: Different Inflation Responses in the Exogenous Investment Model 


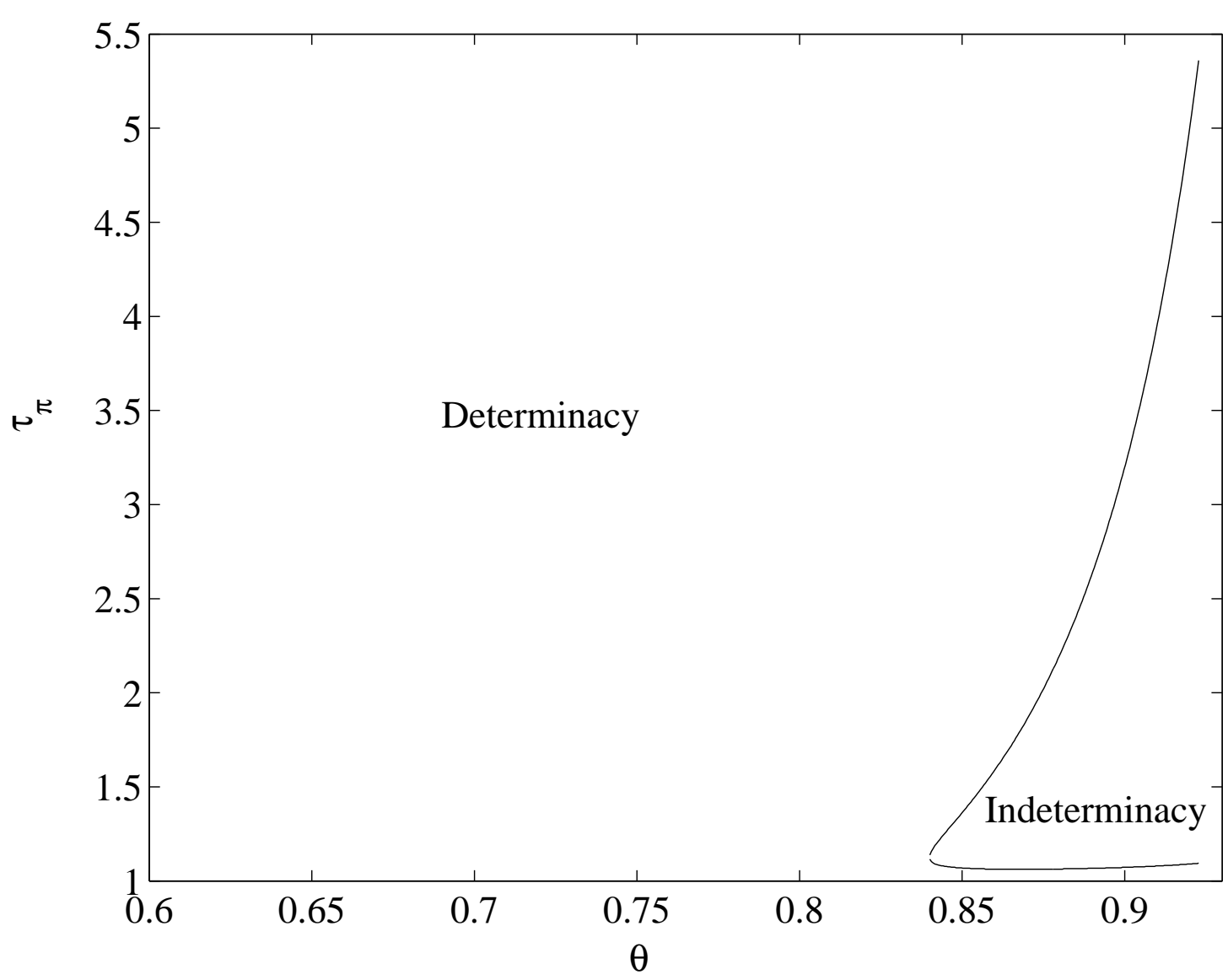

Figure 4: Indeterminacy and the Rental Market 


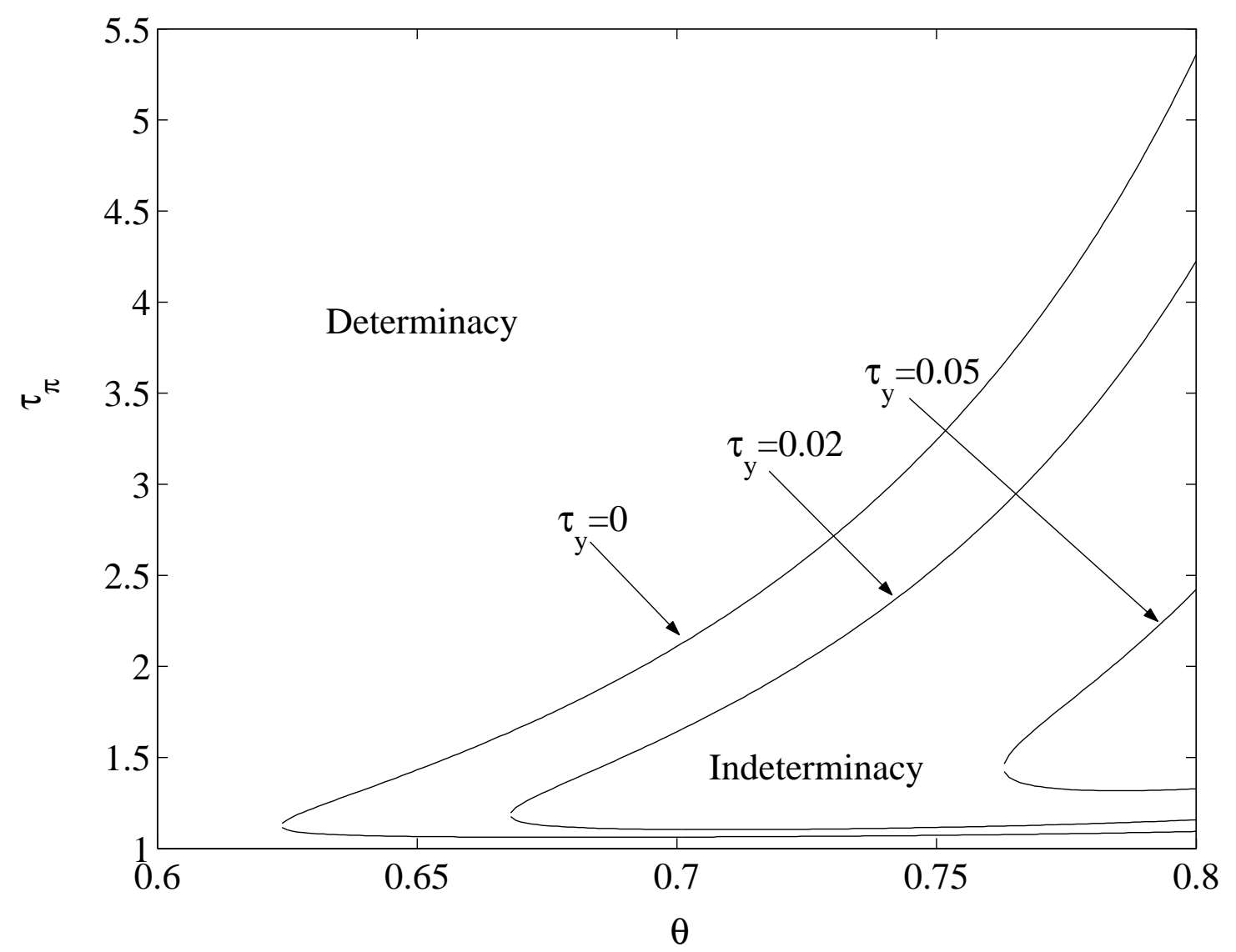

Figure 5: Indeterminacy when Reacting to Output 


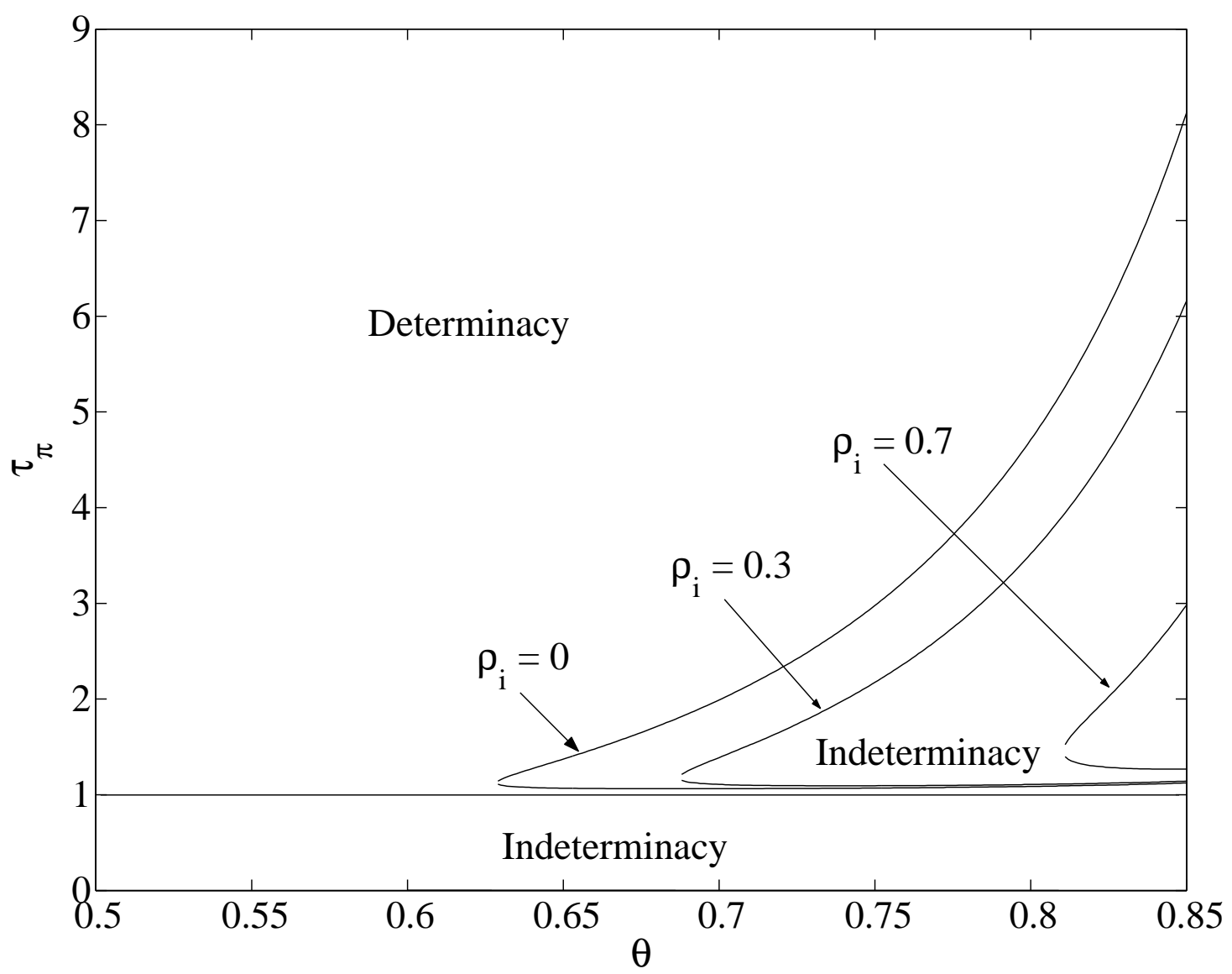

Figure 6: Indeterminacy and Interest Rate Smoothing 